\title{
Difference of Position Change of Sesamoid Bones During Active Abduction Exercise of Great Toe in Subjects with Hallux Valgus
}

\author{
Sung-Joon Yun', Min-Hyeok Kang ${ }^{2}$, Moon-Hwan Kim³ \\ 'Department of Physical Therapy, The Graduate School, Yonsei University, Wonju; ${ }^{2}$ Department of Physical Therapy, Inje University, Busan; \\ ${ }^{3}$ Department of Physical Therapy, The Graduate School, Yonsei University, Wonju, Korea
}

\begin{abstract}
Purpose: The purpose of this study was to investigate the effects of active abduction exercise of the great toe on the medial and lateral sesamoid bones in hallux valgus (HV) patients by measuring radiography.

Methods: In this study 27 young subjects were separated into two groups (normal group and HV group). Two pictures were taken by radiography while maintaining resting and while holding maximal active abduction of the great toe in sitting position on an $\mathrm{x}$-ray table. All radiographs were used to measure the distance of the medial and lateral sesamoid bone from the longitudinal axis of the first metatarsal bone, respectively. Paired t-test was used for analysis of the resting and active abduction exercise in groups. Independent t-test was used to evaluate statistical significance between normal group and HV group. The statistical significance level was $p<0.05$.

Results: In active abduction exercise of the normal group, distance of the medial and lateral sesamoid bones was not significantly different compared to resting condition. In active abduction exercise of the HV group, change of distance of the medial and lateral sesamoid bones showed statistically significant difference compared to resting condition. The distance between the medial sesamoid bone showed a more significant decrease in the HV vs. normal group, while the distance between the lateral sesamoid bone was significantly greater in the HV vs. normal group.
\end{abstract}

Conclusion: These findings suggest that active abduction exercises, to reduce or prevent deterioration of the HV angle, should be considered for sesamoid bone displacement to improve muscle balance in the great toe.

Keywords: Active abduction exercise, Hallux valgus, Radiography, Sesamoid bones

\section{서 론}

엄지발가락의 종자뼈(sesamoid bones)는 첫 번째 발허리뼈머리(metatarsal head)의 아래에 내측 그리고 외측 종자뼈로 구성되어 있다.' 두 개의 종자뼈는 엄지발가락 주위의 근육에 붙임점을 제공한다. 특히 엄지벌림근(abductor hallucis muscle)과 연결되는 짧은엄지굽힘근 (flexor hallucis brevis muscle)의 내측 섬유가 내측 종자뼈에 부착되며, 엄지모음근(adductor hallucis muscle)의 빗갈래와 연결되는 짧은엄지 굽힘근의 외측 섬유는 외측 종자뼈에 부착된다. ${ }^{2-4}$ 또한 내측과 외측 종자뼈 사이에 긴엄지굽힘근(flexor hallucis longus muscle)의 건이 지 나가기 때문에 두 종자뼈의 위치가 긴엄지굽힘근의 적절한 정렬을 유 지시켜준다고 알려져 있으며, 생체역학적으로 보행의 발끝떼기(push off) 시기에 수직으로 내려오는 충격을 두 개의 종자뼈가 흡수하는

Received March 24, 2015 Revised April 17, 2015

Accepted April 19, 2015

Corresponding author Moon-Hwan Kim

E-mail agafimu@hanmail.net
역할을 한다. ${ }^{2.5}$ 이렇게 두 개의 종자뼈에는 여러 가지의 근육이 부착 되기 때문에 이전문헌에서 종자뼈의 위치는 엄지발가락 주위 근육 의 균형을 반영한다고 언급했다. 때문에 종자뼈 위치의 변화는 엄지 발가락의 주위 근육의 불균형으로 인한 엄지발가락의 생체역학적인 움직임의 변화를 초래하며, 종자뼈의 위치변화는 엄지발가락가쪽휨 증(hallux valgus)과 밀접한 관련이 있다고 보고되고 있다.

엄지발가락가쪽휨증은 첫 번째 발허리발가락관절(metatarsophalangeal joint)의 내측통증과 관련이 있는 엄지발가락에서 흔히 일어 나는 질환이다. ${ }^{8}$ 엄지발가락가쪽휨증의 원인으로 내적 요소는 평발, 긴 첫 번째 발허리뼈(metatarsal bone)의 길이, 둥근 첫 번째 발허리뼈 머리의 모양 등이 있으며, 유적적 요소, 그리고 높은 굽의 신발과 발 가락의 제한을 주는 신발의 모양 때문에 발생하는 외적 요소가 있다 고 알려져 왔다.912 또한 내적 요소 중에서 엄지모음근과 엄지벌림근
Copylight (C2015 The Korea Society of Physical Therapy

This is an Open Access article distribute under the terms of the Creative Commons Attribution Non-commercial License (Http:// creativecommons.org/license/by-nc/3.o.) which permits unrestricted non-commercial use, distribution, and reproduction in any medium, provided the original work is properly cited. 
의 근육불균형이 엄지발가락가쪽휨증을 일으키는 중요한 요소로 언급되고 있다. ${ }^{13,14}$ 엄지벌림근의 기능에 관한 연구에서 정상인의 엄 지벌림근과 다르게 엄지발가락가쪽휨증이 있는 환자의 엄지벌림근 은 엄지벌림보다 엄지굽힘의 기능이 더 우세하다고 보고하고 있지만, 정상군과 엄지발가락가쪽휨증군의 엄지벌림근의 단면적에서는 유 의한 차이가 없다고 설명하고 있다. ${ }^{15,16}$ 다른 연구에서 경증 엄지발가 락가쪽휨증 단계에서는 엄지벌림근과 엄지모음근의 근육불균형의 문제를 해결하기 위하여 엄지벌림근의 근력강화운동을 주장하고 있 다.13,14 또한 엄지발가락가쪽휨증이 있는 대상자에게 일정 기간동안 엄지발가락을 능동적으로 벌리는 운동이 엄지발가락가쪽휨 각도를 감소시킨다고 보고하였다. ${ }^{17,18}$ 비록 엄지발가락가쪽휨 각도를 감소시 키기 위하여 실시하는 엄지발가락의 능동적 벌림운동의 효과는 이 전에 연구되었지만, 엄지발가락의 능동적 벌림운동이 엄지발가락의 주변근육의 근육 균형을 반영하는 종자뼈에 어떤 영향을 미치는지 X-ray를 통하여 분석한 연구는 거의 없다. 그러므로 본 실험의 목적은 엄지발가락가쪽휨증이 있는 대상자에게 엄지발가락의 능동적 벌림 운동을 실시했을 때 종자뼈의 위치변화에 어떤 영향을 미치는지 알 아보고자한다.

\section{연구방법}

\section{1. 연구대상}

본 연구에서는 Y대학에 재학중인 학생으로 정상군 12 명(남자: 8명, 여자: 4명) 그리고 엄지발가락가쪽휨증군 15명(남자: 9명, 여자: 6명) 총 27 명의 대상자가 참여했으며, 본 연구에 참여한 모든 대상자는 실 험 전에 본 실험의 목적과 실시방법에 대하여 충분한 설명을 듣고 자 발적으로 참여하였다(Table 1). 먼저 모든 대상자는 X-ray (KOB, Donga X-ray, Anyang, Korea) 테이블 위에서 정상 정렬로 선 자세에서 앞발 (forefoot)을 촬영한 후, 촬영된 방사선 영상으로 엄지발가락가쪽휨 각도를 분석하였다. 엄지발가락가쪽휨 각도가 15 도 미만인 대상자 는 정상군으로 편성하였으며, 15 도 이상인 대상자는 엄지발가락가 쪽휨군으로 선정하였다. ${ }^{18}$ 두 군 모두 발과 발목에 골절 혹은 수술의 과거력, 류마티스 관절염, 심혈관계 질환, 그리고 신경병증 혹은 신경

Table 1. General characteristics of subjects

$(\mathrm{N}=27)$

\begin{tabular}{lcccc}
\hline & Normal group $(n=12)$ & HV group $(n=25)$ & $t$ & $p$ \\
\hline Age (year) & $22.5 \pm 3.3$ & $22.9 \pm 3.7$ & -1.032 & 0.883 \\
Height $(\mathrm{cm})$ & $170.5 \pm 9.3$ & $169.8 \pm 8.8$ & -0.764 & 0.425 \\
Weight $(\mathrm{kg})$ & $64.2 \pm 11.3$ & $65.0 \pm 12.8$ & -1.415 & 0.617 \\
HV angle (year) & $10.5 \pm 3.9$ & $19.2 \pm 3.6$ & -6.537 & $0.000^{*}$ \\
\hline
\end{tabular}

$\mathrm{HV}$, hallux valgus; Mean \pm Standard Deviation.

${ }^{*} p<0.05$.
근육 질환이 있었던 대상자는 본 연구에서 제외하였다.

\section{2. 실험절차}

모든 대상자는 강원도 $\mathrm{W}$ 시에 있는 정형외과에서 X-ray 촬영을 실시 하였다. 먼저 정상군과 엄지발가락가쪽휨증군을 분류하기 위하여 X-ray의 테이블 위에서 정상정렬을 유지한 선 자세에서 X-ray 촬영을 실시하였다. 다음 모든 대상자는 X-ray의 테이블에 의자를 놓고 앉은 상태에서 엉덩관절과 무릎관절을 90 도 유지하고 발과 발가락의 움 직임이 없이 X-ray 촬영을 실시하였고, 같은 자세에서 뒷발의 움직임 이 없이 엄지발가락을 최대한 벌림자세로 유지한 상태에서 하고 Xray 촬영을 하였다. ${ }^{17}$

엄지발가락의 능동적 벌림운동은 양발을 나란히 놓은 상태에서 엄지발가락을 서로 가깝게 모으는 운동이며, 이 운동은 X-ray 촬영을 실시하기 전에 모든 대상자들에게 교육하였다. 선 자세에서 촬영된 X-ray 영상은 엄지발가락가쪽휨증의 유무를 확인하기 위하여 분석 되었다. 엄지발가락가쪽휨증의 각도는 엄지발가락의 발허리뼈의 중 간 세로축을 그은 후에 엄지발가락의 첫마디뼈(proximal phalange)의 중간 세로축을 그었을 때 만나는 사이각으로 결정하였다..$^{19}$ 또한 발가 락에 움직임이 없이 앉아 있을 때와 엄지발가락의 능동적 벌림운동 을 실시하였을 때 내측 그리고 외측 종자뼈의 위치변화를 확인하기 위하여 먼저 내측 종자뼈의 위치는 엄지발가락의 발허리뼈의 중간 세로축에서 내측 종자뼈의 가장 먼 내측지점의 수직거리를 측정하였 고, 외측 종자뼈의 위치는 마찬가지로 엄지발가락의 발허리뼈의 중 간 세로축에서 외측 종자뼈의 가장 먼 외측지점의 수직거리를 측정 하였다(Figure 1). 내측과 외측 종자뼈의 거리는 각각 3 번씩 측정하여 평균값을 분석에 사용하였다. 엄지발가락가쪽휨 각도와 종자뼈의 거리 측정은 Centricity PACS RA1000 workstation (ver. 2.1.0, GE Healthcare Integrated IT Solutions, Barrington, USA)을 이용하여 측정하였다.
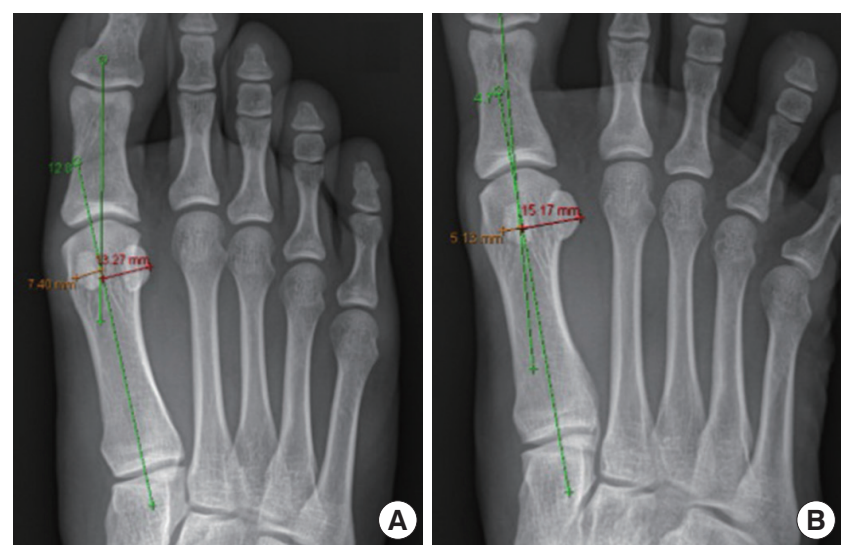

Figure 1. Measurement of distance of MSB and LSB; (A) on rest, (B) active abduction exercise. 
Table 2. Comparison of distance of sesamoid bone between resting and active abduction exercise within group

$(\mathrm{N}=27)$

\begin{tabular}{|c|c|c|c|c|c|c|}
\hline & \multicolumn{2}{|c|}{ Normal group $(n=12)$} & \multicolumn{4}{|c|}{ HV group $(n=15)$} \\
\hline & Resting & AAE & $\mathrm{p}$ & Resting & AAE & $p$ \\
\hline Distance of MSB (mm) & $6.52 \pm 1.57$ & $6.29 \pm 1.42$ & 0.749 & $6.59 \pm 1.79$ & $5.90 \pm 2.03^{*}$ & $0.039^{*}$ \\
\hline Distance of LSB (mm) & $11.86 \pm 1.83$ & $11.73 \pm 1.77$ & 0.932 & $11.53 \pm 1.89$ & $12.33 \pm 1.80^{\star}$ & $0.001^{*}$ \\
\hline
\end{tabular}

$\mathrm{HV}$, hallux valgus; AAE, active abduction exercise; MSB, medial sesamoid bone; LSB, lateral sesamoid bone. ${ }^{*} p<0.05$.

Table 3. Comparison on the difference of resting and active abduction exercise between groups

$(\mathrm{N}=27)$

\begin{tabular}{lrrr}
\hline & Normal group $(\mathrm{n}=12)$ & $\mathrm{HV}$ group $(\mathrm{n}=15)$ & $\mathrm{p}$ \\
\hline Distance of MSB $(\mathrm{mm})$ & $0.04 \pm 1.63$ & $-1.24 \pm 1.98$ & $0.023^{*}$ \\
Distance of LSB $(\mathrm{mm})$ & $0.04 \pm 1.81$ & $1.63 \pm 1.90$ & $0.004^{*}$ \\
\hline
\end{tabular}

$H V$, hallux valgus; AAE, active abduction exercise; MSB, medial sesamoid bone; $L S B$, lateral sesamoid bone.

${ }^{*} p<0.05$.

\section{3. 분석방법}

분석에 사용된 모든 데이터는 평균 \pm 표준편차로 제시하였다. 각 군 내에서 발가락의 움직임없이 앉은자세와 엄지발가락의 능동적 벌림 운동 사이의 내측과 외측 종자빼 거리의 변화는 대응표본 t-검정 (paired t-test)을 사용하였고, 독립표본 t-검정(independent t-test)을 이 용하여 각 군간의 내측과 외측 종자뼈의 움직인 거리의 차이를 비교 하였다. 모든 측정값에 대한 통계학적 분석은 윈도용 SPSS ver. 21.0 프 로그램(SPSS Inc., Chicago, IL, USA)을 이용하여 통계 처리하였으며, 이때 통계학적 유의성 수준은 0.05 로 설정하였다.

\section{결 과}

정상군에서 엄지발가락의 움직임없이 앉은자세와 엄지발가락의 능 동적 벌림운동 사이에서 발허리뼈의 중간 세로축으로부터 내측과 외측 종자뼈의 거리는 유의한 차이가 없었다 $(\mathrm{p}>0.05)$. 그러나 엄지발 가락가쪽휨군내에서 엄지발가락의 능동적 벌림운동을 했을 때 발 허리뼈 중간 세로축으로부터 내측 종자뼈의 거리는 유의하게 감소하 였고, 외측 종자뼈의 거리는 유의하게 증가하였다 $(\mathrm{p}<0.05)$ (Table 2). 또한 정상군과 엄지발가락가쪽휨군 사이에서 발가락의 움직임 없이 앉은자세와 엄지발가락의 능동적 벌림운동 사이에서 내측과 외측 종자뼈의 거리의 차이는 내측 종자뼈에서 유의하게 감소하였고 $(\mathrm{p}<0.05)$, 외측 종자뼈에서는 유의하게 증가하였다 $(\mathrm{p}<0.05)$ (Table 3$).$

\section{고 찰}

본 연구에서는 엄지발가락가쪽휨증이 있는 환자에게 엄지벌림근을 강화시키는 운동인 엄지발가락의 능동적 벌림운동이 내측과 외측
종자뼈에 어떤 영향을 미치는지 X-ray 통하여 확인하였으며, 엄지발 가락가쪽휨증군은 정상군보다 발허리뼈 중간 세로축으로부터 내측 종자뼈의 거리는 유의하게 감소하였고, 외측 종자뼈는 유의하게 증가 하였다. 이전 근전도 연구에서, Arinci Incel 등'13은 정상인보다 엄지발 가락가쪽휨증이 있는 환자는 엄지벌림근과 엄지모음근에서 근활성 도가 감소하지만 엄지모음근보다 엄지벌림근에서 근육의 약화가 더 욱 두드러지기 때문에 엄지발가락에서는 엄지모음의 힘이 더욱 크게 작용한다고 설명하고 있다. Cralley 등는 엄지발가락가쪽휨 각도와 엄지벌림근의 약화는 높은 상관관계를 보이기 때문에 엄지발가락가 쪽휨 각도가 증가할수록 엄지벌림근의 근력의 약화로 인하여 엄지 모음근의 당기는 힘은 증가한다고 보고하고 있다. 그러므로 엄지발 가락가쪽휨증군에서 엄지모음근의 근력이 엄지벌림근의 근력보다 우세하기 때문에 엄지발가락의 능동적 벌림운동을 실시했을 때, 내 측 종자뼈의 위치는 엄지발가락 발허리뼈의 세로축에 가까워지고, 외측 종자뼈의 위치는 반대로 멀어지는 결과를 보였다고 사료된다. Hetherington ${ }^{22}$ 은 내측 종자뼈가 엄지발가락 발허리뼈의 세로축에 가 까워지는 것은 내측 종자뼈가 발바닥 방향으로 이동한 것이고, 반면 에 외측 종자뼈가 세로축에서 멀어지는 것은 외측 종자뼈가 발등 방 향으로 움직인 것이며, 이는 두 개의 종자뼈가 외측방향으로 이동했 음을 의미한다고 설명했다. 또한 발바닥 방향으로 내측 종자뼈의 움 직임은 내측 종자뼈와 발바닥쪽발허리능선(plantar metatarsal crista) 의 퇴행성변화가 일어날 수 있으며, 두 종자뼈의 외측 이동은 내측곁 인대(medial collateral ligament)와 내측종자뼈인대(medial sesamoidal ligament)가 신장되어 내측인대의 약화나 미세찢어짐(microtear)을 초 래할 수 있다.22,23

정상군의 경우, 발가락의 움직임 없이 앉아있을 때와 능동적 발가 락 벌림 운동을 실시했을 때 두 개의 종자뼈의 거리에는 유의한 차이 가 없었던 이유는 두 개의 종자뼈에 부착하는 엄지벌림근과 엄지모 음근 사이의 근균형이 유지되기 때문이라고 사료되며, 이전 근전도 연구에서 정상군에서는 엄지벌림근과 엄지모음근의 균형이 유지된 다는 보고를 뒷받침한다. ${ }^{13}$

이전 연구에서, 엄지발가락가쪽휨증 환자에게 엄지벌림근의 근력 을 증가시키기 위한 운동으로 엄지발가락의 능동적 벌림운동을 실 시하고 그 효과를 연구했었다.1718 BAYAR 등21은 운동군에서는 엄지 
발가락의 벌림운동을 그리고 실험군에서는 엄지발가락 벌림운동 플 러스 테이핑을 각각 4주간 실시하여 측각계(goniometer)를 이용하여 효과를 비교했었는데 엄지발가락 벌림운동군에서 엄지발가락가쪽 휨 각도가 1.6-2.1도 감소하였다. 그러나 아직까지 엄지발가락가쪽휨 증의 운동효과가 종자뼈에는 어떠한 영향을 미치는지 X-ray 촬영을 이용하여 연구한 실험은 아직 없다.

본 연구에서 사용한 X-ray 촬영은 엄지발가락가쪽휨 각도를 측정 하거나 엄지발가락가쪽휨의 수술 전 그리고 수술 후의 변화를 측정 하기 위해 사용되고 있으며, X-ray 촬영을 이용한 분석은 자기공명영 상 검사에 비해 경제적이며, 정확한 측정방법이라고 언급되었다.24,25

이전에 몇몇 연구에서 엄지발가락가쪽휨 각도를 감소시키거나 증 가되는 것을 방지하기 위한 운동이 추천되거나 운동방법을 연구했 었다. ${ }^{17,18}$ 그러나 본 연구에서 엄지발가락가쪽휨증군은 능동적 엄지 발가락 벌림운동을 실시하였을 때, 엄지발가락 주변근육의 근균형 을 반영하는 두 개의 종자뼈가 정상군보다 외측으로 이동하였고, 이 는 엄지모음근이 엄지벌림근보다 우세적으로 작용했으리라 판단되 며, 반복적으로 지속적인 엄지발가락의 벌림운동은 두 개의 종자뼈 의 위치에도 부정적인 영향을 미칠 수 있으리라 사료된다. 그러므로 엄지발가락가쪽휨 각도를 감소시키기 위해서나 혹은 엄지발가락가 쪽휨 각도가 더욱 증가하는 것을 방지하기 위한 운동을 실시할 때 엄 지발가락의 근균형을 나타내는 종자뼈의 움직임도 함께 고려하여 실시해야 할 것이라고 제안한다.

본 연구의 제한점으로는 대상자가 모두 20대로써 모든 연령의 엄 지발가락가쪽휨증이 있는 모든 환자에게 일반화하기에 어려움이 있 고, X-ray를 이용하여 촬영하고 이를 분석하여 종자뼈의 위치 변화를 통하여 엄지벌림근과 엄지모음근의 기능을 유추하였다. 따라서 추 후 다양한 연령대의 대상자로 종자뼈의 위치변화없이 엄지벌림근을 강화시킬 수 있는 방법이 연구되어야 한다고 사료된다.

\section{REFERENCES}

1. Suwannahoy P, Srisuwan T, Pattamapaspong N, et al. Intra-articular ossicle in interphalangeal joint of the great toe and clinical implication. Surg Radiol Anat. 2012;34(1):39-42.

2. Thomson SA. Hallux varus and metatarsus varus: a five-year study (1954-1958). Clin Orthop. 1960;16:109-18.

3. Martin BF. Observations on the muscles and tendons of the medial aspect of the sole of the foot. J Anat. 1964;98:437-53.

4. Becerro de Bengoa Vallejo R, Losa Iglesias ME, Jules KT. Tendon insertion at the base of the proximal phalanx of the hallux: surgical implications. J Foot Ankle Surg. 2012;51(6):729-33.

5. Donatelli RA. The Biomechanics of the Foot and Ankle. 2nd ed. Philadelphia, F. A. Davis Company, 1996:26-31.

6. Huang EH, Charlton TP, Ajayi S, et al. Effect of various hallux valgus re- construction on sesamoid location: a radiographic study. Foot Ankle Int. 2013;34(1):99-103.

7. Shereff MJ, Bejjani FJ, Kummer FJ. Kinematics of the first metatarsophalangeal joint. J Bone Joint Surg Am. 1986;68(3):392-8.

8. Dufour AB, Casey VA, Golightly YM, et al. Characteristics Associated with Hallux Valgus in a Population-Based Study of Older Adults: The Framingham Foot Study. Arthritis Care Res (Hoboken). 2014;66(12): 1880-6.

9. Munuera PV, Polo J, Rebollo J.: Length of the first metatarsal and hallux in hallux valgus in the initial stage. Int Orthop. 2008;32(4):489-95.

10. D’Arcangelo PR, Landorf KB, Munteanu SE, et al. Radiographic correlates of hallux valgus severity in older people. J Foot Ankle Res. 2010;3:20.

11. Piqué-Vidal C, Solé MT, Antich J. Hallux valgus inheritance: Pedigree research in 350 patients with bunion deformity. J Foot Ankle Surg. 2007; 46(3):149-54.

12. Klein C, Groll-Knapp E, Kundi M, et al. Increased hallux angle in children and its association with insufficient length of footwear: a community based cross-sectional study. BMC Musculoskelet Disord. 2009; 10:159.

13. Arinci Incel N, Genç H, Erdem HR, et al. Muscle imbalance in hallux valgus: an electromyographic study. Am J Phys Med Rehabil. 2003;82(5): 345-9.

14. Iida M, Basmajian JV. Electromyography of hallux valgus. Clin Orthop Relat Res. 1974;(101):220-4

15. Kim MH, Koh EK, Jung DY. Analysis of kinematic motions of first metatarsophalangeal joint during electrical stimulation of abductor hallucis muscle in subjects with hallux valgus. J Kor Phys Ther. 2012;24(4): 276-81

16. Kang SY, Choung SD, Kim MH, et al. Relationship between angle of metatarsophalangeal joint and abductor hallucis in hallux valgus. J Kor Phys Ther. 2014;26(2):56-61.

17. Groiso JA: Juvenile hallux valgus. A conservative approach to treatment. J Bone Joint Surg Am, 1992;74(9):1367-74.

18. Bayar B, Erel S, Şimsek, İE, et al. The effects of taping and foot exercises on patients with hallux valgus: A preliminary study. Turk J Med Sci. 2011;41(3):403-9.

19. Choi GH, Park KY, Byun SJ, et al. Study on Angular Correlation between Hallux Valgus and 1st MPJ Dorsi-flexion according to Work Type and Age of Woman. J Kor Phys Ther. 2011;23(5):57-63.

20. Srivastava S, Chockalingam N, El Fakhri T. Radiographic measurements of hallux angles: A review of current techniques. Foot (Edinb). 2010;20(1):27-31

21. Cralley JC, McGonagle W, Fitch K. The role of adductor hallucis in bunion deformity (Part II). J Am Podiatry Assoc. 1978;68(7):473-83.

22. Hetherington VJ: Hallux Valgus and Forefoot Surgery. New York: Churchill Livingstone, 1994:42-54.

23. Grode SE, McCarthy DJ. The anatomical implications of hallux abducto valgus: a cryomicrotomy study. J Am Podiatry Assoc. 1980;70(11):539-51.

24. Srivastava S, Chockalingam N, El Fakhri T. Radiographic measurements of hallux angles: A review of current techniques. Foot (Edinb). 2010b; 20(1):27-31.

25. Lee IH, Park HJ, Jin JS, et al. comparison of radiography findings and magnetic resonance image findings of lumbar spine instability patients. J Kor Phys Ther. 2007;19(3):41-6. 